\title{
Burkitt lymphoma mimicking acute pancreatitis
}

\author{
Lívia Moscardi Bacchia, Ivan Ucella ${ }^{b}$, Thiago Trolez Amancioa, Marianne de Castro Gonçalvesa, \\ Renata Bacic Palhares ${ }^{a}$, Sheila Aparecida Coelho Siqueira ${ }^{a}$
}

Bacchi LM, Ucella I, Amancio TT, Gonçalves MC, Palhares RB, Siqueira SAC. Burkitt lymphoma mimicking acute pancreatitis. Autopsy Case Rep [Internet]. 2012;2(3):5-11. http://dx.doi.org/10.4322/acr.2012.020

\section{ABSTRACT}

\begin{abstract}
Burkitt lymphoma $(\mathrm{BL})$ is a highly aggressive $B$ cell lymphoma, presenting in extranodal sites or as an acute leukemia. Three clinical variants of $B L$ are recognized: endemic $B L$, sporadic $B L$ and immunodeficiency associated $B L$. Sporadic $B L$ is seen worldwide, mainly in children and young adults involving the abdominal organs mostly the ileocaecal area. Pancreatic involvement is rare. The authors report a unique case of abdominal Burkitt lymphoma, initially diagnosed and treated as acute pancreatitis. Clinically, the patient presented severe abdominal pain and vomiting. Imaging findings were suggestive of inflammatory involvement of the pancreas, heading treatment towards this hypothesis. Unfortunately, the patient died during the diagnostic work up, and the autopsy findings demonstrated advanced Burkitt lymphoma with extensive involvement of pancreatic parenchyma and other organs within the abdominal cavity. Once Burkitt lymphoma is a potentially curable disease, early diagnosis is crucial for better outcomes.
\end{abstract}

Keywords : Burkitt lymphoma; Pancreatitis; Autopsy; Lymphoma, B-Cell.

\section{CASE REPORT}

A 76-year-old Brazilian male was admitted to the emergency room complaining of twoweeks epigastric abdominal pain, sporadic fever and weight loss accompanied by nausea and vomiting. The patient had a history of type II insulindependent diabetes mellitus, chronic hypertension and non-dialytic chronic renal failure. He denied alcohol or smoking abuse. Two months ago, he was hospitalized with the diagnosis of hepatic and splenic abscesses with blood culture positive to Staphylococcus aureus. On physical examination the patient was eutrophic and looking well. He was afebrile, pulse rate $=92$ beats per minute, blood pressure $=150 / 80 \mathrm{mmHg}$ and slight edema was palpable on lower limbs. Pulmonary examination showed rales on both lung bases. Abdominal examination revealed a generalized tenderness more pronounced on the epigastrium and left upper quadrant. The liver was palpable up to $4 \mathrm{~cm}$ below the right costal margin. Heart examination was unremarkable.

The results of laboratory tests on admission are summarized in Table 1, showing pancytopenia with slight elevation of amylase and lipase.

\footnotetext{
a Department of Pathology - Faculdade de Medicina - Universidade de São Paulo, São Paulo/SP - Brazil.

${ }^{b}$ Department of Pathology - Hospital A. C. Camargo, São Paulo/SP - Brazil.
}

Copyright $\odot 2012$ Autopsy and Case Reports - This is an Open Access article distributed of terms of the Creative Commons Attribution NonCommercial License (http://creativecommons.org/licenses/by/3.0/) which permits unrestricted non-commercial use, distribution, and reproduction in any médium provided article is properly cited. 
Abdominal ultrasonography ruled out the presence of hepatic abscess. The gallbladder wall was thick and micro calculi were evidenced in its interior. The pancreas was diffusely enlarged showing a heterogeneous texture compatible with an acute inflammatory process. A peripancreatic hyper echogenic tissue, which extended diffusely through the retro peritoneum, was also evidenced. This examination was complemented by a total abdominal and pelvic computed tomography (CT), which revealed a diffuse enlargement of the pancreas surrounded by a solid infiltrative tissue, extensive to the splenic, hepatic hilum as well as to the retro peritoneum, which was interpreted as being of inflammatory nature. The presence of a considerable amount of peritoneal fluid also was noted (Figure 1 and 2). Considering the clinical and radiological findings, treatment for acute pancreatitis was undertaken.

As no clinical improvement was achieved after four days of appropriate treatment, the patient was submitted to a paracenthesis. The cytological analysis of the peritoneal fluid showed suspicious cells for malignancy along with a high number of necrotic or degenerated lymphoid cells. On the thirteenth day of hospitalization the patient underwent a needle retroperitoneal biopsy. One hour after this procedure, he experienced acute dyspnea, lung congestion, hypotension, cardiac arrest, and died. An autopsy was performed.

\section{AUTOPSY FINDINGS}

On external examination, the anthropometric measures revealed the body of a mulatto man,
$172 \mathrm{~cm}$ tall and weighing $67 \mathrm{~kg}$ (body mass index of $22 \mathrm{~kg} / \mathrm{m}^{2}$ ). Upon the opening of the abdominal cavity, a huge retroperitoneal tumor mass was observed readily, which extended from the liver to the pelvic region. It was $17 \times 15 \mathrm{~cm}$ in size showing mostly white areas alternating with foci of yellow areas. The mass also involved the external surface of the right kidney and adrenal as well as splenic arteries and veins, prostate, portal vein, gallbladder, inferior vena cava, aorta, stomach, duodenum, colon, spleen, liver, pancreas and bladder (Figure 3).

The histological examination of the tumor revealed a neoplastic lymphoid proliferation with a

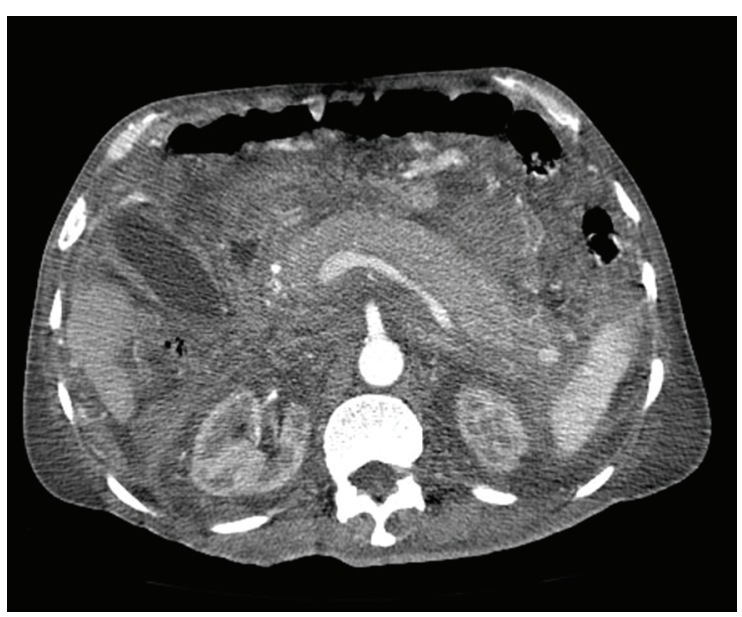

Figure 1 - Axial computed tomography of the abdomen, after intravenous contrast injection. Note diffuse thickening of the pancreas without ductal dilatation or collections. There is diffuse thickening and densification of the mesenteric and retroperitoneal fat tissues, more evident along the posterior contour of the pancreas and bilateral anterior pararenal region. The superior mesenteric vein is patent.

Table 1 - Laboratory workup on admission

\begin{tabular}{cccccc}
\hline Exam & Result & RV & Exam & Result & RV \\
\hline Hemoglobin & 8.7 & $12.3-15.3 \mathrm{~g} / \mathrm{dL}$ & Creatinine & 2,24 & $0.7-1.2 \mathrm{mg} / \mathrm{dL}$ \\
Hematocrit & 28.8 & $36-45 \%$ & AST & 79 & $<37 \mathrm{U} / \mathrm{L}$ \\
Leukocytes & 3.72 & $4.4-11.3 .10 \% / \mathrm{L}$ & ALT & 8 & $<41 \mathrm{U} / \mathrm{L}$ \\
Bands & 0 & $1-5 \%$ & LDH & 704 & $105-333 \mathrm{U} / \mathrm{L}$ \\
Segmented & 70 & $45-70 \%$ & Amylase & 149 & $28-100 \mathrm{U} / \mathrm{L}$ \\
Eosinophils & 1 & $1-4 \%$ & Lipase & 136 & $13-60 \mathrm{U} / \mathrm{L}$ \\
Basophils & 0 & $0-2.5 \%$ & Albumin & 3.0 & $3.4-4.8 \mathrm{~g} / \mathrm{dL}$ \\
Lymphocytes & 18 & $18-40 \%$ & Total Ca+ & 10.3 & $8,6-10,2 \mathrm{mg} / \mathrm{dl}$ \\
Monocytes & 11 & $2-9 \%$ & CRP & 5.1 & HIV \\
Platelets & 102 & $150-450.10 \% / \mathrm{L}$ & negative & $<5 / \mathrm{m}$
\end{tabular}

$\mathrm{ALT}=$ alanine aminotranspherase, $\mathrm{AST}=$ aspartate aminotranspherase, $\mathrm{Ca}+=$ calcium $\mathrm{CRP}=\mathrm{C}$ reactive protein, $\mathrm{LDH}=$ lactate dehydrogenase, $\mathrm{RV}=$ reference value. 


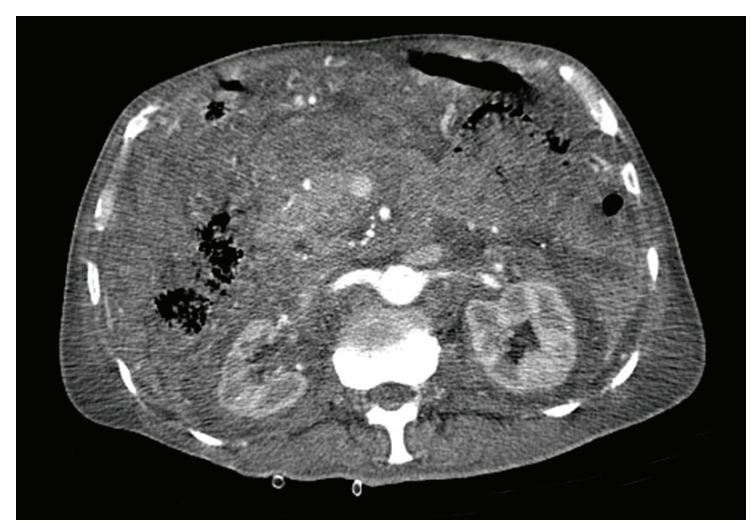

Figure 2 - Axial computed tomography after intravenous contrast injection. Note thickening of the pancreatic uncinate process without ductal dilatation or collections. There is diffuse thickening and densification of the mesenteric and retroperitoneal fat tissues, most evident around the pancreatic head and right parietocolic gutter. The vessels are patent.

diffuse and monotonous growth. The tumor cells were medium to small size with round nucleus, inconspicuous multiple nucleoli, numerous mitotic figures and a high number of apoptotic bodies (Figure 4).

There was also neoplastic infiltration of the gastric wall, bone marrow and pancreatic parenchyma (Figure 4 and 5). The biopsy performed on the day the patient died demonstrated similar microscopic findings. The right and left lungs weighed $700 \mathrm{~g}$ and $510 \mathrm{~g}$, respectively (normal range $325-570 \mathrm{~g}$ ). The external surface of both lungs was smooth, grey, with anthracotic deposits. On cut sections, there was pulmonary congestion and edema, which was confirmed by histological examination (Figure 5).

Acute pulmonary edema was considered the immediate cause of death. Immunohistochemistry studies were performed on tissue sections of the tumor mass revealing expression of CD20 and CD10 with proliferation index (Ki-67) of $100 \%$. There was no expression of BCL-2. CD3 was positive only in non-neoplastic T cells (Figure 6). LMP1-EBV by immunohistochemistry was negative. In situ hybridization for EBV was performed and was negative. The evaluation of the translocation of gene MYC was not performed. In the present case, the morphological and immunohistochemical findings were diagnostic of Burkitt lymphoma (BL).

\section{DISCUSSION}

The autopsy findings confirmed the diagnosis of $\mathrm{BL}$ with extensive infiltration of the pancreatic parenchyma, as well as other organs and vascular structures in the retroperitoneal region.

First described by Dennis Burkitt in 1958, $B L$ is a highly aggressive B cell lymphoma, often presenting in extranodal sites or as an acute leukemia. ${ }^{1}$ It is composed of monomorphic mediumsized transformed cells with basophilic cytoplasm and high mitotic rate. Immunophenotypically, BL is characterized by expression of CD20, CD10, BCL-6 and membranous $\lg \mathrm{M}$, with no expression of $\lg \mathrm{D}$, BCL-2 and terminal deoxynucleotidyl transferase (TdT). The Ki-67 proliferation index generally approaches $100 \%{ }^{2}$

Three clinical variants of $B L$ are recognized: endemic $B L$, sporadic $B L$ and immunodeficiency associated BL. Endemic BL is the form that occurs in African children, involving the mandible and other facial bones in $50 \%$ of the cases. Sporadic BL is seen throughout the world, mainly in children and young adults. ${ }^{3-5}$ In this form of BL, the abdomen, especially the ileocaecal area, is the most common site of involvement. ${ }^{6}$ The immunodeficiency associated $\mathrm{BL}$ occurs in the setting of HIV infection and also has been observed in allograft recipients and in congenital immunodeficiency. It accounts for a third of non-Hodgkin lymphoma in HIV positive patients. ${ }^{7}$ Burkitt lymphoma often represents the initial AIDSdefining illness. ${ }^{7}$ Our case represents BL of sporadic form, as the patient had no immunodeficiency of any kind.

Burkitt lymphoma is estimated to account for only 1 to $5 \%$ of all non-Hodgkin lymphomas in adults. The Netherlands Cancer Registry data ${ }^{8}$ indicates that the distribution of $\mathrm{BL}$ is bimodal with a peak between 0 and 15 years and a later peak over 60 years of age.

Burkitt lymphoma is associated with EpsteinBarr virus (EBV) infection. ${ }^{9}$ The association between $E B V$ and $B L$ varies in frequency depending on the clinical variant. EBV is present in up to $100 \%$ of the endemic cases, in fewer than $30 \%$ of cases of sporadic $\mathrm{BL}^{6}$ and in 30 to $40 \%$ of immunodeficiency related BL. ${ }^{10}$ The absence of LMP1-EBV by immunohistochemistry in our case does not rule out the association with EBV as the latent membrane protein- 1 of the EBV is usually not expressed in $B L$ 

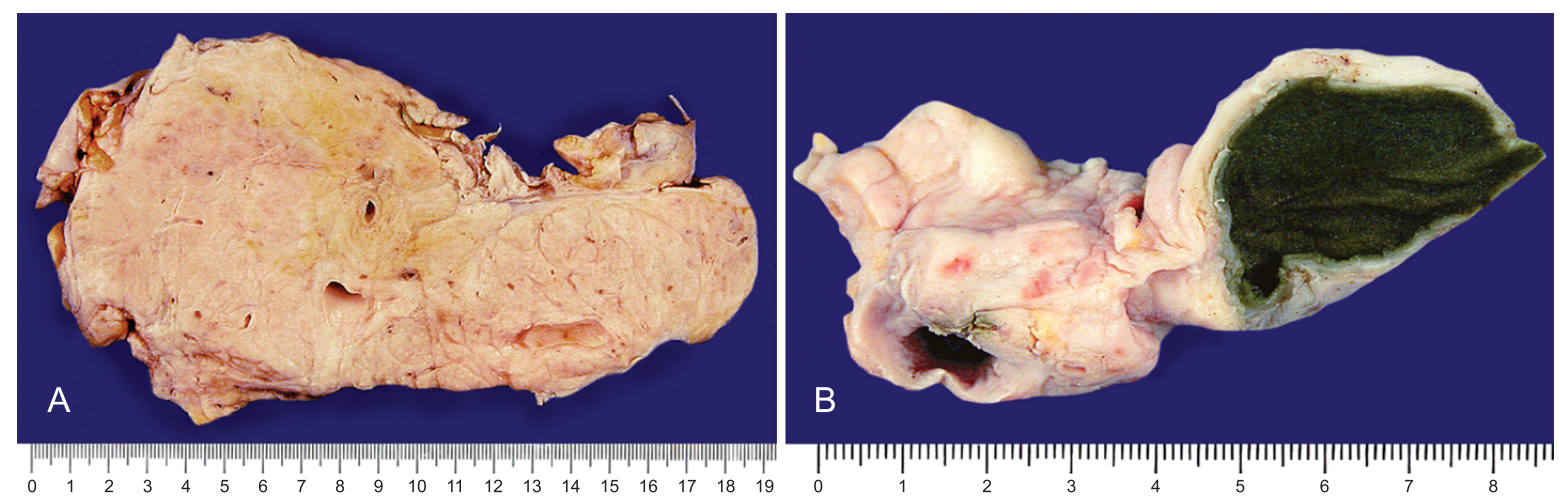

H or
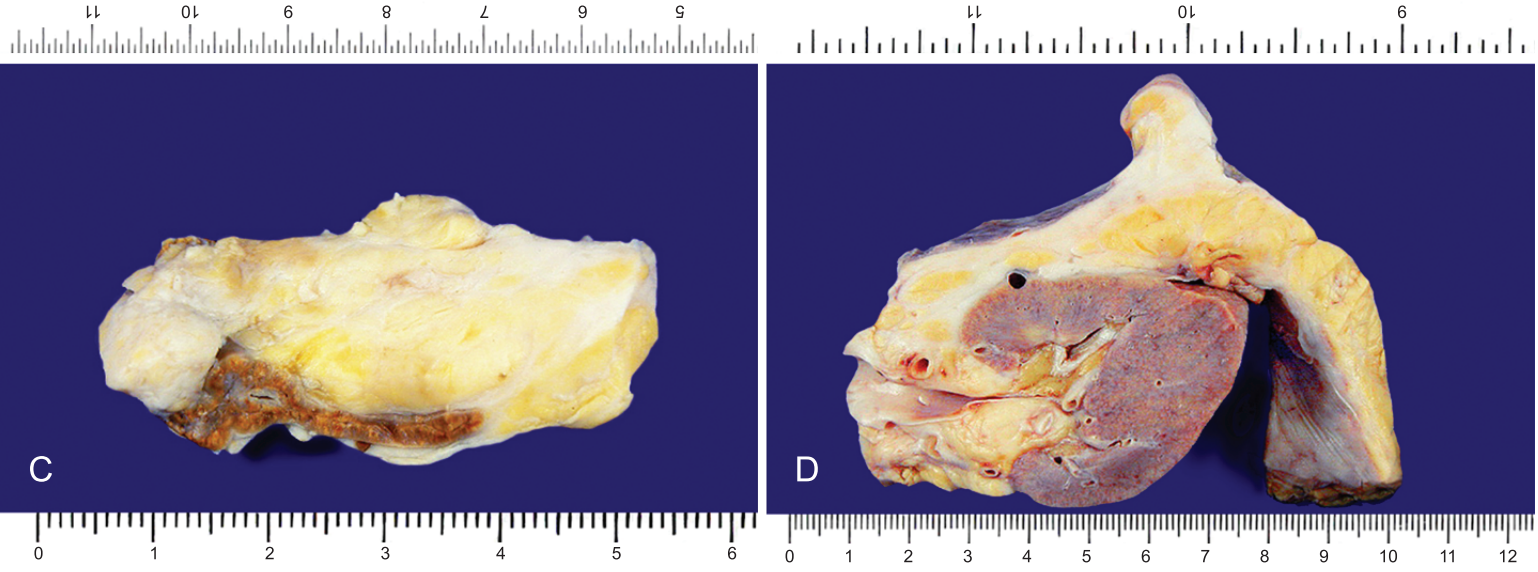

$, 1,1,1,1,1,1,1,1,1,1,1,1,1,1,1, l_{1}^{1}, 1,1,1,1,1$

H. or

or 6

8

Figure 3 - Gross findings - A - Enlarged and diffusely, infiltrated and deformed pancreas by Burkitt lymphoma; B - Infiltration of the gallbladder wall and the structures of hepatic hilum by Burkitt lymphoma; C - Involvement of right periadrenal tissue by Burkitt lymphoma; D - Involvement of the right kidney tissue by Burkitt lymphoma.

neoplastic cells. The evaluation of EBV by in situ hybridization was also negative. The evaluation of the translocation of gene MYC was not performed. The main reason for evaluating this translocation, in this context, would be for the differential diagnosis with diffuse large $B$ cell lymphoma (DLBCL). ${ }^{11}$ However, DLBCL has the MYC translocation in 15 to $20 \%$ of the cases. Although this translocation is very frequent in Burkitt lymphoma, up to $10 \%$ of cases the mutation is not found. In summary, the presence or absence of the translocation would not assure the diagnosis of Burkitt lymphoma or DLBCL.

Although the terminal ileum is the most frequently described intra-abdominal location for $\mathrm{BL}$, many other sites within the abdomen can be involved. ${ }^{12}$ Common findings, especially in children, include hepatic, renal, retroperitoneal, and mesenteric lymph node involvement. ${ }^{13}$ The pancreas, however, is an uncommon site involved by $\mathrm{BL}$. Imaging findings of pancreatic $\mathrm{BL}$ include focal and infiltrative lesions. When BL occurs in the pancreas, the most commonly involved anatomic area is the head of the pancreas. The biliary tract may be dilated by compression of the pancreatic mass, what was not observed in this case report.

In our patient, the tumor infiltrated the wall of the gallbladder, as previously described in the literature. ${ }^{12}$ Both CT and ultrasound are useful imaging modalities for evaluating the pancreas. Magnetic resonance imaging and positron emission tomography scans also have been used. ${ }^{12}$ However, in some situations, differentiation between pancreatitis and tumoral pancreatic involvement may be challenging. ${ }^{14}$ Burkitt lymphoma mimicking acute pancreatitis is rare, but few cases were described in adults and children. ${ }^{14}$ Pancreatic involvement in Burkitt lymphoma is uncommon ${ }^{15}$ and may be a manifestation of widely disseminated and advanced disease, as it was in this case. ${ }^{15,16}$ Because BL is one of the most rapidly growing tumors with a cellular doubling time of about 24 hours ${ }^{17}$, it requires prompt diagnosis for initiation of treatment. Endemic and sporadic $\mathrm{BL}$ is highly aggressive but potentially curable. ${ }^{1}$ Intensive combination chemotherapy regimens result in cure rates of up to $90 \%$ in patients with low stage disease ${ }^{18}$ and in 60 to $80 \%$ 


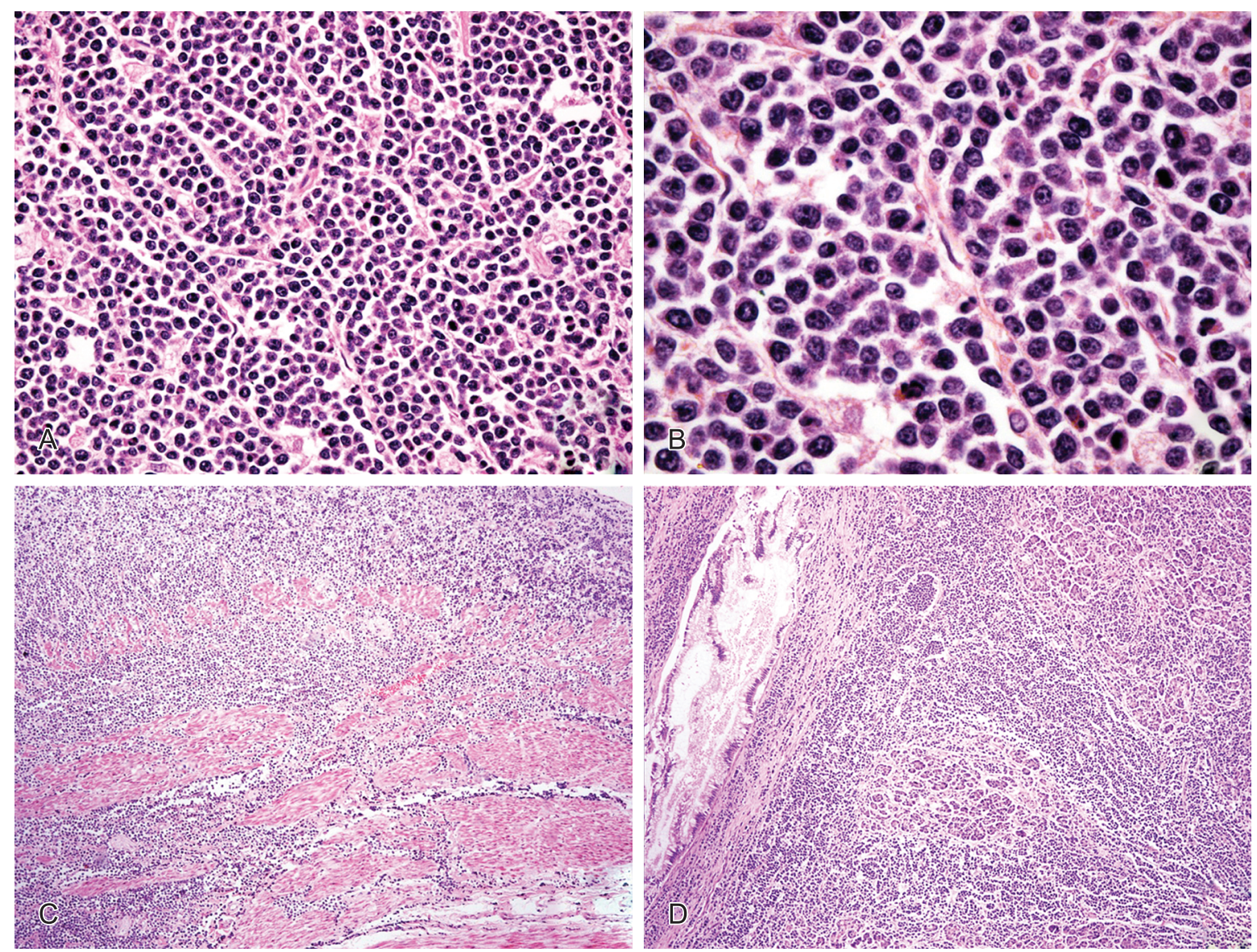

Figure 4 - Microscopy findings. A - Retroperitoneal infiltration by diffuse proliferation of medium-sized atypical lymphoid cells (HE; 200x); B - Higher power of previous figure showing cytological details (HE; 400x); C - Gastric wall heavily infiltrated by lymphomatous cells (HE; 100x); D - Pancreatic parenchyma densely infiltrated by Burkitt lymphoma cells; in the center of the field there is a pancreatic islet (HE; 200x).
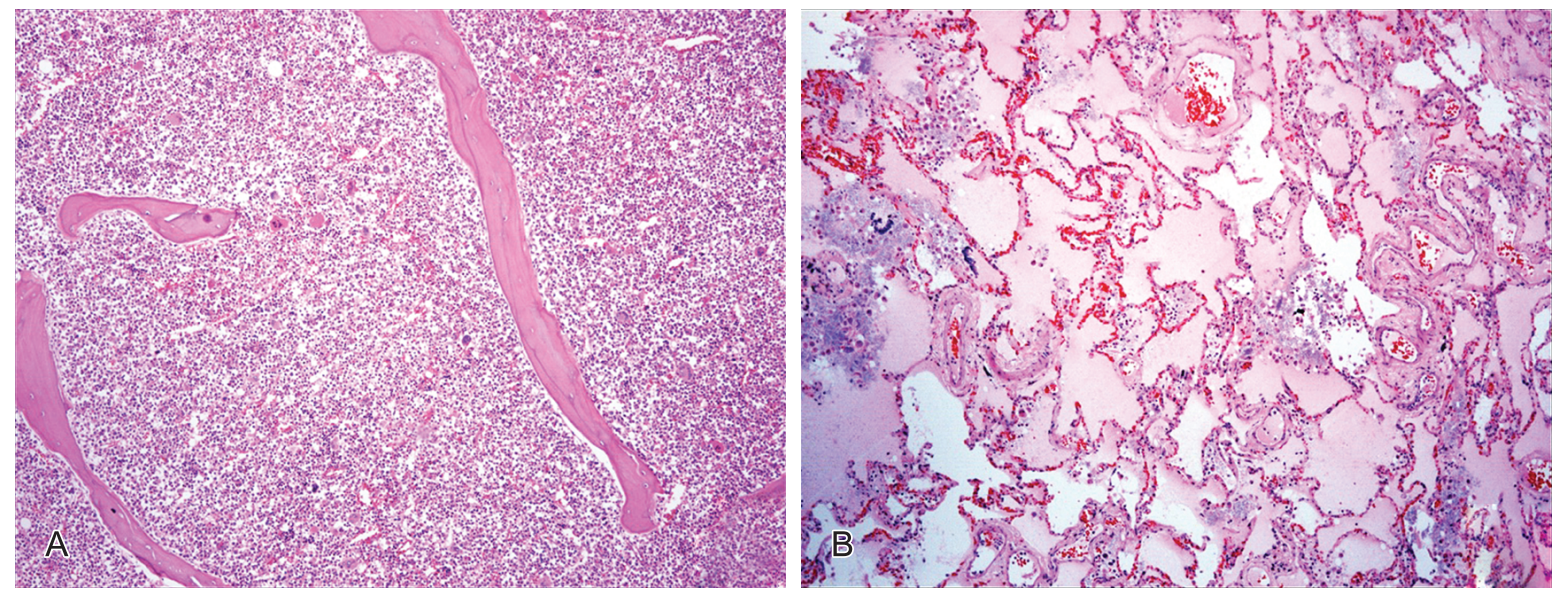

Figure 5 - Photomicrography. A - Bone marrow revealing hypercellularity mainly due to interstitial infiltration by Burkitt lymphoma (HE; 100x); B - Cut section of the pulmonary parenchyma with diffuse alveolar edema (HE; 100x).

in patients with advanced disease. ${ }^{4,19}$ Because it is potentially curable, it is important to consider BL when confronted with a pancreatic mass although it is not among the leading differential diagnosis. ${ }^{14}$
In conclusion, $\mathrm{BL}$, as well as other types of B-cell lymphoma, when involving the pancreas may express a clinical picture of pancreatitis. This case presentation illustrates how the autopsy findings can 

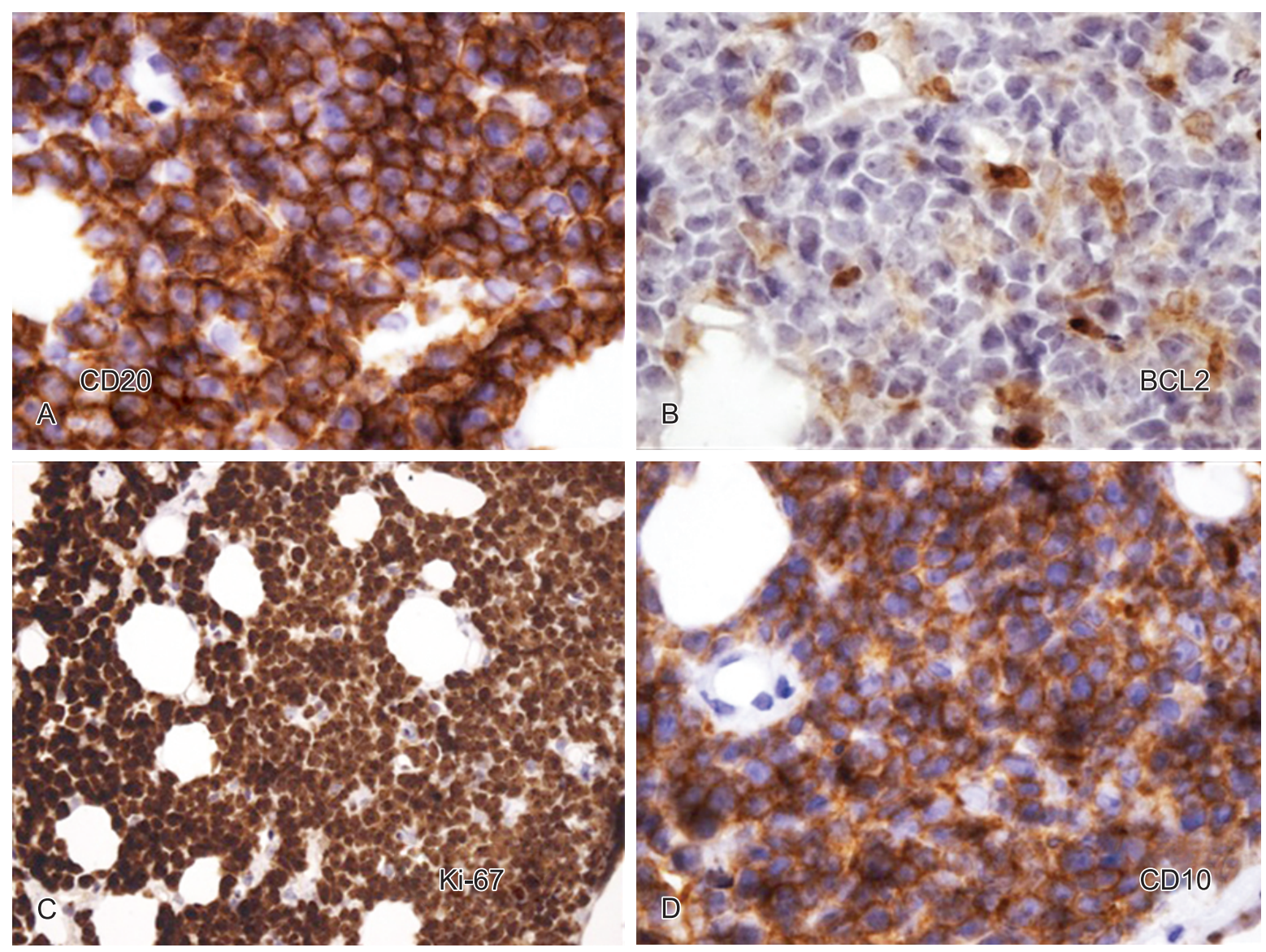

Figure 6 - Photomicrography - Immunohistochemistry. Burkitt lymphoma cells expressing CD20 (400x) and CD10 (400x) with high proliferating index by Ki-67 $=100 \%(200 \times)$ and absence of expression of BCL2 $(400 \times)$.

elucidate the clinical dilemma. It should be stated, however, that this clinical presentation, mimicking acute pancreatitis, is extremely unusual for BL.

We report herein a case of BL in a 76-yearold man who was admitted to the emergency room with severe abdominal pain and vomiting episodes. Ultrasonography disclosed the presence of biliary micro lithiasis, computed tomography findings suggested inflammatory involvement of the pancreas and serum amylase and lipase determination were slightly increased. Therefore the treatment was directed towards the diagnosis of acute pancreatitis. Without clinical improvement, the patient died thirteen days after admission due to an acute pulmonary edema. In an autopsy setting, it is difficult to point out the exact cause of pulmonary edema. In our case, no specific myocardial lesion was found, even though we speculate that, due to the history of hypertension and diabetes the patient most probably presented some degree of heart ischemia. ${ }^{20}$

This case report also exemplifies one of the purposes of the autopsy, which is the improvement of the care quality. Physicians very often are surprised by the autopsy's findings, justifying its performance even in cases of apparent no doubt in the diagnosis.

\section{REFERENCES}

1. Swerdlow SH, Campo E, Harris NL, et al., editors. WHO classification of tumours of haematopoietic and lymphoid tissues. 4th ed. Lyon: International Agency of Research on Cancer; 2008.

2. Chuang SS, YE H, Du MQ, et al. Histopathology and immunohistochemistry in distinguishing Burkitt Lymphoma from diffuse large B-cell lymphoma with a very high proliferation index and with or without a starry-sky pattern: a comparative study with EBER and FISH. Am J Clin Pathol. 2007;128:558-64. PMid:17875505.

3. Burkitt DP. A sarcoma involving the jaws in African children. Br J Surg. 1958; 46:218-23. http://dx.doi.org/10.3322/ canjclin.22.6.349

4. Magrath IT, Janus C, Edwards BK, et al. An effective therapy for both undifferentiated (including Burkitt's) lymphomas and lymphoblastic lymphomas in children and young adults. Blood. 1984;63:1102-11. PMid:6546890. 
5. Wright DH. Burkitt's lymphoma: a review of the pathology, immunology and possible etiological factors. Pathol Annu. 1971;6:337-63. PMid:4342309.

6. Jaffe ES, Harris NL, Stein H, Vardimnn JW, editors. Pathology and genetics of tumours of haematopoietic and lymphoid tissues. Lyon, France: IARC Press; 2001. World Health Organization Classification of Tumours.

7. Navarro WH, Kaplan LD. AIDS-related lymphoproliferative disease. Blood. 2006;107:13-20. http://dx.doi.org/10.1182/ blood-2004-11-4278

8. Boerma EG, van Imhoff GW, Appel IM, Veeger NJ, Kluin PM, Kluin-Nelemans JC. Gender and age-related differences in Burkitt lymphoma: epidemiological and clinical data from The Netherlands. Eur J Cancer. 2004;40:2781-7. http://dx.doi. org/10.1016/j.ejca.2004.09.004

9. Epstein MA, Achog BG, Barr YM. Virus particles in cultured lymphoblasts from Burkitt's lymphoma. Lancet. 1964;1:702-3. http://dx.doi.org/10.1016/S0140-6736(64)91524-7

10. Kelly GL, Rickinson AB. Burkitt lymphoma: revisiting the pathogenesis of a virus-associated malignancy. Hematology. 2007;277-84. PMid:18024641.

11. Naresh KN, Ibrahim HA, Lazzi S, et al. Diagnosis of Burkitt lymphoma using an algorithmic approach - applicable in both resource-poor and resource-rich countries. $\mathrm{Br} \mathrm{J}$ Haematol. 2011;154:770-6. PMid:21718280.

12. Aftandilian CC, Friedmann AM. Burkitt Iymphoma with pancreatic involvement. J Pediatr Hematol Oncol. 2010;32:e338-40. http://dx.doi.org/10.1097/ MPH.0b013e3181ed1178
13. Biko DM, Anupindi SA, Hernandez A, Kersun L, Bellah R. Childhood Burkitt lymphoma: abdominal and pelvic imaging findings. AJR Am J Roentgenol. 2009;192:1304-15. http:// dx.doi.org/10.2214/AJR.08.1476

14. Amodio J, Brodsky JE. Pediatric Burkitt lymphoma presenting as acute pancreatitis: MRI characteristics. Pediatr Radiol. 2010;40:770-2. PMid:20135116.

15. Toma P, Granata C, Rossi A, Garaventa A. Multimodality imaging of Hodgkin's disease and non-Hodgkin's lymphomas in children. Radiographics. 2007;27:1335-54. http://dx.doi. org/10.1148/rg.275065157

16. Ng YY, Healy JC, Vincent JM, Kingston JE, Armstrong P, Reznek RH. The radiology of non-Hodgkin's lymphoma in childhood: a review of 80 cases. Clin Radiol. 1994;49:594-600. PMid:7955884.

17. Ferry JA. Burkitt's Iymphoma: clinicopathologic features and differential diagnosis. Oncologist. 2006;11:375-3. http:// dx.doi.org/10.1634/theoncologist.11-4-375

18. Patte $C$, Auperin A, Gerrard M, et al. Results of the randomized international $\mathrm{FAB} / \mathrm{LMB} 96$ trial for intermediate risk B-cell non-Hodgkin's lymphoma in children and adolescents: it is possible to reduce treatment for the early responding patients. Blood. 2007;109:2773-80. http://dx.doi.org/10.1182/ blood-2006-07-036673

19. Soussain C, Patte C, Ostronoff M, et al. Small noncleaved cell lymphoma and leukemia in adults: a retrospective study of 65 adults treated with LMB pediatric protocols. Blood. 1995;85:664-74. PMid:7833470.

20. Ware LB, Matthay MA. Acute pulmonary edema. N Engl J Med. 2005;353:2788-96.

\section{Conflict of interest: None}

Submitted on: $21^{\text {th }}$ May 2012

Accept on: $23^{\text {th }}$ August 2012

Correspondence: Lívia Moscardi Bacchi

Alameda Jaú, 1477, apto 1131B - Jardim Paulista - São Paulo/SP - Brazil

CEP: 01420-006

E-mail: libacchi@yahoo.com.br 
